\title{
El discurso administrativo y la tradición pragmática
}

\section{David Galicia Osuna}

Profesor investigador, Facultad de Estudios Superiores Cuautitlán, UNAM davidgaliciao@gmail.com

\section{Resumen}

La administración y su discurso no pueden ser considerados ciencia y teoría porque no cumple criterios de teoricidad, contrastación, falsación, deductibilidad y axiomatización. En este ensayo se propone ubicar al discurso administrativo dentro de la tradición pragmática, particularmente por las similitudes que tiene con esta tradición; asimismo, se argumenta que el discurso administrativo pone atención en los resultados, en lo útil, en lo que permite alcanzar los objetivos, en la satisfacción de los deseos, en lo eficaz, en lo prudencial, en la racionalidad instrumental (medio-fin) y en la búsqueda del lucro mientras que, al mismo tiempo, subordina cuestiones epistemológicas como criterios de verdad, teoricidad, deducibilidad y coherencia, contrastación de hipótesis y búsqueda de la verdad. Reflexionar sobre las proposiciones del discurso administrativo y su relación con la realidad más allá de los resultados es necesario para avanzar hacia la teorización de la administración.

Palabras clave: discurso administrativo, tradición pragmática, verdad, lucro. 


\title{
Administrative discourse and pragmatic tradition
}

\begin{abstract}
Administration and its discourse cannot be deemed as science and theory since it does not meet the theoricity, contrastation, refutation, deductibility and axiomatization criteria. In this paper I propose to locate the administrative discourse within the pragmatic tradition, particularly because of its similarities with this tradition. It is argued that the administrative discourse focuses on results, usefulness, goals achievement, desine gratification, effectiveness, prudence, instrument rationality (means-end) and for-profit objectives. At the same time it subordinates epistemological issues such as truth, theoricity, deductibility and coherence criteria, hypothesis contrastation and the search for truth. A reflection is necessary on the administrative discourse propositions and their relation to reality beyond results. This is necessary in order to advance towards the theorization of administration.
\end{abstract}

“[...] volvernos pragmatistas - identificar el sentido de la vida con obtener lo que se desea, con imponer nuestra voluntad."

“[...] desplazarnos hacia la concepción de Nietzsche de que <<las categorías de la razón>> no son más que $<<$ medios hacia la adaptación del mundo para fines utilitarios $>>$."

Richard Rorty

\section{Introducción}

Este trabajo busca darle un lugar más acertado al discurso administrativo y responder a la pregunta: ¿en qué tradición de investigación podemos ubicarlo?, pues no se le puede llamar con claridad teoría administrativa porque no cumple con criterios de teoricidad. A los teóricos de la administración y la organización pareciera no preocuparles las cuestiones epistemológicas, ${ }^{1}$ como criterios de demarcación entre lo qué es ciencia y lo que no lo es (verificación, falsación, deductibilidad, axiomatización); no se ven interesados por reflexionar acerca del contexto de descubrimiento y el contexto de justificación; no se preocupan por problemas de la inducción, ni por criterios de teoricidad, coherencia, deductibilidad, ni por el criterio de verificación o contras-

\footnotetext{
${ }^{1}$ Ni preocupados por el bien común. Muy de cerca del individualismo, liberalismo y evolucionismo darwinista de Hayek.
} 
tación. De igual manera, parecieran no interesados en las propuestas de Popper y el problema de la falsación e interpretación, ni por las preocupaciones epistemológicas de los programas de investigación que señala Imre Lakatos, el concepto de carga teórica de Laudan, el problema del holismo de Pierre Duhem, el relativismo de Paul Feyerabend y Thomas Kuhn, el realismo de Ian Hacking y Hilary Putnam, el problema de la verdad de Richard Rorty, entre otros. Parecen alejados de las reflexiones acerca de la relación de sus proposiciones con la realidad más allá de los resultados. Es por ello que se puede ubicar de forma "natural" al discurso administrativo en la tradición pragmática. Defender esta tesis es la idea que guía este trabajo.

Llamarle teoría científica al discurso administrativo siempre deja algunas dudas epistemológicas respecto a los criterios establecidos por los filósofos de la ciencia, ya sea positivistas, neopositivistas, realistas y aun pospositivistas, especialmente si pensamos en el contexto de descubrimiento — el problema de la inducción- y de justificación —el problema de la verificación. Asimismo, llama la atención la extraña "coherencia" del proceso administrativo y la convivencia de enunciados diversos, en su interior, que hablan sobre planeación, organización, integración, dirección y control, según el modelo de cinco elementos.

El discurso administrativo parece que más que preocuparse por cumplir las exigencias epistemológicas, que señalan los filósofos de la ciencia, positivistas y realistas, parece estar más preocupado por los resultados (Gannon, 1994), la eficiencia, la eficacia y la calidad, así como por alcanzar los objetivos organizacionales, la búsqueda de la ganancia, el lucro, la rentabilidad, la competitividad, el poder y dominio en la competencia de los mercados. Todo ello alejado de igual forma del bien común, muy cerca del pensamiento de Friedrich A. Hayek y Milton Friedman. Ello debido a que este discurso administrativo emerge en un estado capitalista, no socialista, distinto a la propuesta de Karl Polanyi, caracterizado especialmente por una racionalidad económica².

\footnotetext{
${ }^{2}$ Hay que tener en cuenta que la racionalidad económica se refiere a la obtención del máximo beneficio en la empresa capitalista que Adam Smith ya proponía con claridad. Se puede entender como un principio económico al principio general del comportamiento racional. Ello incluye, como parte de la racionalidad instrumental, el adecuar de forma óptima los medios a los fines. Frente a una "economía natural", se busca obtener el máximo beneficio con respecto a la inversión. Dicha racionalidad privilegia la intencionalidad del individuo. El contexto conceptual liberal en su vocabulario, además del respeto a la propiedad y la vida, se encuentra en la libertad que John Locke propuso. Frente a modelos deterministas, se privilegia la libertad e intencionalidad. La racionalidad económica tiene que ver con el concepto de libertad del individuo, donde el individuo elige libremente y donde el papel del Estado debe ser proteger esa libertad.
} 
Por ello, en lugar de ciencia o técnica, al discurso administrativo le podemos llamar tradición de investigación, mismo que se ubica en otra: la tradición pragmática. Esta ubicación puede permitirnos entender su escasa preocupación por cumplir con criterios serios de cientificidad y preocuparse más por el superávit. Al fundarse en una premisa medio-fin o racionalidad instrumental, el discurso administrativo se ubica de forma "natural" en la tradición pragmática3.

\section{El concepto de tradición}

El concepto de tradición científica de investigación de Laudan se refiere al conjunto de presupuestos ontológicos, epistemológicos y metodológicos que guían la formulación, evaluación y desarrollo de las teorías científicas que pertenecen a esa tradición. Las tradiciones de investigación científica (TIC) orientan la evaluación, esto es, la aceptación, rechazo o modificación de teorías heredadas, formuladas y desarrolladas dentro de la tradición en cuestión. También las TIC constituyen recursos para la confrontación dialógica con otras tradiciones y afirma que tales confrontaciones son fundamentales para el desarrollo racional de las tradiciones de investigación.

El concepto de tradiciones de investigación de Laudan, pese a que ayuda a entenderlo, tiene un referente teórico científico que le queda muy estrecho al discurso administrativo. Se refiere fundamentalmente a teorías "bien hechas", como es el caso de las ciencias naturales. Por ello, debiéramos pensar en un concepto de tradición como el que Gadamer propone - como la transmisión histórica de sentidos y significados en el que se logra la síntesis del pasado y del porvenir; en el pasado se funda toda comprensión (Gadamer, 1998: 336)—, lo cual permitiría complementar, por su flexibilidad, al concepto de tradición de Laudan, por ser aquél, más sociológico.

\footnotetext{
${ }^{3}$ La tradición liberal tiene como premisas la libertad y el concepto de individuo egoísta. Adam Smith y después Milton Friedman presentaban ya esos conceptos, en particular el de la elección racional. En esta concepción liberal, los individuos, libremente y racionalmente, tienden a maximizar sus utilidades a reducir sus costos o riesgos; los individuos prefieren más lo bueno y menos lo que les cause mal. Los individuos buscan, libre y racionalmente, optimizar y mejorar sus condiciones. El individuo debe ser guiado por su interés personal. Todo individuo tiene capacidad racional para elegir la mejor línea de conducta. Como la propuesta de Richard Rorty que afirma, desde su pragmatismo, hacer lo que se desea. Citemos a Richard Rorty (1993: 49-77):

Esto significa que la única forma en que podemos seguir la empresa de Platón es volvernos pragmatistas -identificar el sentido de la vida con obtener lo que se desea, con imponer nuestra voluntad. La única cosmología que podemos afirmar con certeza nos recomendó Platón es nuestra propia cosmovisión (comunitaria o individual), nuestra forma de disponer las cosas para su manipulación, la forma que dictan nuestros deseo.
} 
En general, la filosofía de la ciencia pospositivista concibe a las tradiciones científicas como una serie de teorías e hipótesis que se desarrollan de manera continua, a través de determinados procesos metodológicos y dialógicos, y de acuerdo con ciertos presupuestos ontológicos y epistemológicos específicos de la tradición. Con ello, se pretende resaltar el aspecto histórico sobre el metodológico de la actividad de las comunidades científicas. Ese carácter histórico (Gannon, 1994) se puede mostrar en las diferentes tradiciones que han enriquecido al discurso administrativo como lo es la teoría "científica", la clásica, la burocrática, el humanorelacionista, la neoclásica, o la de contingencias.

Conviene ver a la tradición (Velasco, 2004) como complejos de conceptos, de teorías, interpretaciones, creencias, normas, prácticas, valores y estándares de evaluación en un determinado ámbito de la acción y del conocimiento. Habría que sumar que las tradiciones tienen un origen contingente, pero gracias a su continuidad en el tiempo adquieren arraigo histórico y autoridad suficiente para orientar y evaluar las creencias y prácticas de sus adherentes.

Es en el proceso administrativo donde podemos encontrar tal complejo de conceptos, de teorías, de interpretaciones. Al adentrarnos en el concepto de planeación se pueden encontrar diversos conceptos como misión, objetivos, estrategias, normas, políticas, valores, así como "teorías" como planeación estratégica (Thompson, 2001).

En este sentido, se podría decir que el discurso administrativo como proceso administrativo es una tradición, tanto por ser un conjunto de conceptos, de teorías, interpretaciones, normas, prácticas, valores y estándares de evaluación en el ámbito de acción de las organizaciones y del conocimiento administrativo; como por haber tenido continuidad en el tiempo, enriqueciéndose, llegando a tener arraigo histórico y autoridad para orientar y evaluar las creencias y prácticas de sus adherentes. Este concepto de tradición desde luego nos recuerda al menos a Gadamer y a Laudan, aunque es un concepto más flexible como el viejo concepto de ideología, como conjunto de creencias o ideas acerca del mundo de la sociedad y del ser humano, que no se valora por su coherencia, sino por su practicidad. En el caso de Gadamer tenemos en mente el concepto heideggeriano de precomprensión que se refiere a una forma histórica de comprender el mundo (de ser en el mundo), aunque no inconmensurable. El discurso administrativo es una forma de comprender que nos permite ser en el mundo organizacional. 


\section{El discurso administrativo y la tradición pragmática}

El discurso administrativo se aleja de las exigencias epistemológicas de las ciencias naturales y sociales. Sus intereses y preocupaciones lo podrían ubicar en una tradición más general, el pragmatismo, como ideología. La familia de enunciados o prejuicios del pragmatismo puede adoptar por su contenido a la otra familia de enunciados, la del discurso administrativo.

La tradición pragmática es una familia de enunciados ${ }^{4}$ amplia que puede admitir también al discurso administrativo. Como se afirma más adelante: para un pragmático, los constructos teóricos no se juzgan con criterios de verdad o falsedad, sino más bien por su utilidad y eficacia, como instrumentos, dependiendo de su capacidad para proporcionar un control del mundo observable y la posibilidad de obtener lo que se desea. El criterio de "verdad" es el criterio de lo mejor a la luz de los resultados, llámesele, entre otras cosas, productividad, calidad, sobrevivencia, eficiencia, eficacia, rentabilidad, ganancia, productos o servicios. Todo esto se encuentra en el espíritu del discurso administrativo.

De igual manera, toda evaluación de teorías científicas (Velasco: 2004) es contextual, referente a la tradición a la que pertenece. Se puede hablar de diferentes tradiciones administrativas como la clásica o la científica o cualquier otra como la humano-relacionista, ninguna es la mejor universalmente, sino de acuerdo con el contexto.

Por otra parte, el análisis de la racionalidad de las decisiones del discurso administrativo, en su pragmatismo, desborda el ámbito de la metodología que exige la verificación o falsación —al estar más preocupado por los resultados, no por la verdad de la proposición - y necesariamente se inscriben en el ámbito de la deliberación prudencial más criterios pragmáticos de éxito práctico que sopesa las ventajas y desventajas de los recursos de la tradición, discurre en torno a la conservación o cambio de los elementos de la tradición a la que pertenece. No busco la teoría ver-

\footnotetext{
${ }^{4}$ Toda tradición, toda teoría se puede considerar como un conjunto de enunciados constatativos y realizativos. Las proposiciones remiten a una racionalidad metódica, que señala proposiciones que pueden ser contrastados con la realidad, además de explicar y predecir. Pero una tradición, como se señala también Alasdair MacIntyre comprende normas, valores, prácticas, esto es, elementos de una racionalidad normativa. Por ello se puede hablar de una familia de enunciados de forma más amplia. Puede resultar interesante ver el capítulo "La racionalidad de las tradiciones" de MacIntyre (1994).
} 
dadera, la científica, sino la que mi prudencia me señala como la adecuada ¿Por qué no considerar el Tao o quizá la inteligencia emocional, por qué no el conductismo, o mejor el psicoanálisis, por qué no a Weber o el sentimiento religioso? En este sopesar, qué me es más útil, no sólo cuentan los éxitos, la aplicación exitosa, sino también el potencial heurístico, esto es me permite evaluar conceptos, teorías, guiar mi investigación, descubrir nuevos hechos, plantear nuevos métodos, formular soluciones innovadoras, modificar creencias, en función de los resultados.

Algunos elementos que se encuentran en la tradición pragmática, como en la de Rorty (1993), se observan también en la tradición administrativa, como es el caso de lo histórico de las tradiciones, que Idalberto Chiavenato presenta: 1) el criterio de utilidad, de lo mejor a la luz de los resultados, sobre el de verdad; 2) la importancia de lo contextual frente a criterios universalistas positivistas; 3) la deliberación prudencial, no algorítmica —en el sentido de no seguir un procedimiento estricto y un solo camino, como el único verdadero- de una tradición científica dejando a un lado los criterios estrictos positivistas; y 4) la consideración del potencial heurístico y práctico de una tradición, aun la religiosa.

Figura 1

Similitud conceptual entre pragmatismo y discurso administrativo

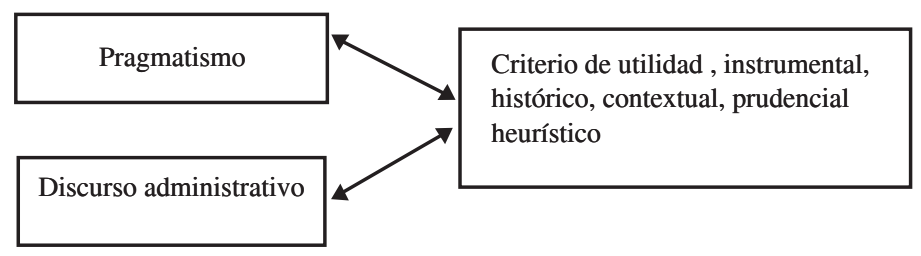

\section{Algunas ideas del pragmatismo que comparte el discurso administrativo}

En filosofía de la ciencia se encuentran diversas tradiciones generales de investigación como son realismo, relativismo, positivismo y pragmatismo. Cada una de ellas con presupuestos ontológicos, epistemológicos y metodológicos con respecto a cómo entender, construir y justificar el conocimiento y aplicarlo.

La tesis que sostengo es que la tradición pragmática parece ser la más adecuada para incluir el discurso administrativo en ella, especialmente por su manera de entender diversos conceptos como instrumentalismo, "verdad", conocimiento y de utilidad como criterio de saber exitoso. 
Heidegger (1993) afirma que “[...] el ser es algo que está ahí en la medida que está la verdad y la verdad está sólo en la medida en que está el Dasein. Ser y verdad son igualmente primordiales." Esto nos acerca un poco a la idea del sofista Protágoras que afirmaba que el hombre es la medida de todas las cosas. Lo cual puede llevar a la idea relativista de que hay tantos seres como verdades hay, y verdades como humanos hay ${ }^{5}$. Pero desde luego, estas afirmaciones relativistas llevan a un extremo peligroso el concepto de ser y verdad. Heidegger no pretendía ello, pretendía explicar que el ser o realidad que depende de alguna verdad histórica es siempre producto humano, el cual siempre está en un contexto: ser-en-el-mundo. Con la modernidad, las explicaciones teológicas sobre el ser fueron abandonadas, recordándonos que la verdad es una construcción humana, la de cualquier ámbito, ético, religioso, estético, político, social y desde luego de la ciencia moderna. De igual forma, Heidegger dice que la verdad es histórica, frente a cualquier absolutismo o fundamentalismo que se pretende/asume como transhistórico. Estas ideas son retomadas por algunos pragmáticos como Richard Rorty. A continuación veamos algunas ideas del pragmatismo que parecen aplicarse al discurso administrativo.

Instrumentalismo: Dos pragmáticos importantes, William James y John Dewey, desarrollaron esta tesis, al igual que Richard Rorty. Las tesis instrumentalistas son antirrealistas al considerar que las teorías científicas no son más que herramientas para organizar la descripción de los fenómenos y hacer inferencias aplicables. El componente teórico no describe la realidad, ellas son instrumentos útiles destinados a relacionar un conjunto de observables con otros, es decir, no se preocupan por especulaciones teóricas, sino de lo que arroja resultados visibles. La ciencia es considerada como instrumento, cuyo objetivo es producir teorías y conceptos, capaces de superar contrastes empíricos más exigentes, lo que las hace más fiables. Las mejores teorías son las que han superado pruebas fuertes y son útiles como guías fiables para conseguir explicaciones y predicciones exitosas. Esto también caracteriza al discurso administrativo cuyos conceptos son herramientas para la solución de problemas prácticos. Por tanto, más importante que la explicación es la predicción de las teorías, considerando especialmente sus resultados exitosos, más que la verdad. Más que estar preocupados por la verdad o falsedad de las proposiciones que componen una teoría, habría que considerar que estas proposiciones deben habilitarnos para hacer predicciones observables. No es la verdad o la falsedad de esas proposiciones la que nos debe ocupar, sino la adecuación de una teoría al

\footnotetext{
${ }^{5}$ Mi postura, siguiendo a Alasdair MacIntyre, es que hay tantas verdades como tradiciones hay o se han dado.
} 
problema o necesidad que queremos satisfacer, esto es, si quiero elevar el desempeño de mis trabajadores, no importa si los motivo con enunciados religiosos, con utopías o promesas que no cumpliré. Las proposiciones en una teoría contribuyen para algún propósito o no, si ocurre lo primero son necesarios, de lo contrario pueden ser desechables o guardados para otro momento y lugar. El "neoclasicismo administrativo" de Koontz dejaría ver ello (Koontz y Weihrich: 2002), recuerda que el objetivo de los administradores de negocios es simple: lograr una ganancia. Para ello es fundamental la organización del conocimiento en las cinco funciones conocidas. Esta estructuración del conocimiento ha mostrado resultados exitosos en las organizaciones, pues la aplicación del proceso administrativo en las empresas ha sido útil para elevar las ganancias.

Criterio de demarcación: La postura positivista especialmente ponía dos jueces para separar lo que pertenece a la ciencia y lo que no pertenece. El criterio de demarcación era importante para ello. Aquel enunciado que cumpliera con el criterio de demarcación pertenecería a la ciencia. Primero, el contexto de descubrimiento proponía que todo enunciado que fuese científico tendría que provenir de la observación de hechos individuales, y por inducción, al encontrar algo común, un patrón, generalizar, o producir un enunciado universal. Segundo, el contexto de justificación que propone que de un enunciado universal se deduciría una hipótesis que predijera algún hecho, y que se verificara (o contrastara, falsara) con la realidad y que si resultaba exitosa era verdadera la hipótesis y la teoría de la cual se dedujo. Con ello se afirmaba que el único camino válido para el conocimiento era el de la ciencia. La inducción era un criterio de demarcación, por un lado; por otro, lo era la corroboración o falsación, en términos de Popper. Con respecto al criterio de demarcación, los pragmáticos son más flexibles, admiten que la ciencia no es el único camino válido por el conocimiento, muy cerca de posturas relativistas y contra el positivismo y el realismo. Algunos afirman que el pragmatismo es una postura intermedia entre el realismo —que considera que la ciencia es la única vía para el conocimiento- y el relativismo que indica que no existe una sola verdad. La sugerencia pragmática de no vincularse a ningún saber — no porque se llame ciencia — remite a lo que James sugería: métete al cuarto que necesites meterte, llámese metafísica, ciencia o religión ${ }^{6}$, sino métete al que te permita el éxito. El criterio de demarcación es la utilidad, lo que permita satisfacer [mis] preferencias, necesidades o deseos, individuales, organizacionales o sociales. Criterio que no sería ajeno al discurso administrativo. Salvador Mercado

\footnotetext{
${ }^{6}$ Por ejemplo, hay que recordar que el 12 de diciembre se festeja a la Virgen de Guadalupe en algunas empresas, lo cual tiene, como medio, consecuencias favorables para los fines de la organización.
} 
(1990) sugiere que un gerente calificado como un verdadero ejecutivo tiene que lograr una productividad eficiente del grupo que dirige. Para ello necesita hacer uso de cuatro elementos o funciones útiles de la administración: planeación, organización, dirección y control.

La verdad. El realista entiende el concepto de verdad como teoría de la verdad como correspondencia entre enunciado y realidad, y los enunciados de una teoría como espejo de la naturaleza; pero los pragmáticos normalmente prefieren hablar de otra cosa. Para un realista, las descripciones del mundo observable pueden ser verdaderas o falsas dependiendo de que lo describan correctamente o no. En cambio, para un pragmático, los constructos teóricos no se juzgan con criterios de verdad o falsedad, sino más bien por su utilidad como instrumentos, dependiendo de su capacidad para proporcionar un control del mundo observable. El criterio de la verdad es el criterio de lo mejor — entendido en este caso como lo racional— para obtener lo que se desea o el máximo beneficio a la luz de los resultados. Richard Rorty es quien desarrolla mejor este escepticismo respecto a la verdad; considera que la búsqueda de la verdad no es más que un sueño dogmático cuentista. Lo verdadero viene a significar aproximadamente lo que puedes defender frente a cualquiera que esté presente. Para él, como pragmático, las ciencias no presentan verdades objetivas del mundo. La ciencia como fuente de la verdad es una noción cartesiana que se desvanecerá. Los científicos lo que hacen es presentar teorías "inconmesurables" y eso constituye su conversación. La historia de la ciencia puede mostrar como ociosa la búsqueda de la verdad porque es un panteón de teorías.

Certeza. La tradición fue iniciada por Platón con la búsqueda de la certeza y continuó hasta la modernidad con el giro cartesiano hacia la subjetividad, en la búsqueda de lo imposible: "Yo pienso", "Pienso, luego existo". Ahora con el escepticismo, el relativismo, el realismo de Putnam y el pragmatismo parece que sólo podemos estar seguros de qué queremos. Lo único realmente evidente para nosotros son nuestros propios deseos. Un enunciado será cierto o "verdadero" si permite satisfacer nuestros deseos: individuales o sociales. Lo que le da sentido a la vida es lo que deseamos. La única cosmología (Rorty, 1993: 49-77) cierta o "verdadera" es nuestra propia cosmovisión (comunitaria, organizacional o individual), nuestra forma de disponer de las cosas para su manipulación y la forma que dictan nuestros deseos. Heidegger afirma a propósito:

Comprendida esencialmente, la cosmovisión no significa una imagen del mundo sino el mundo concebido y captado como imagen. Lo que es, en su totalidad, se concibe ahora de 
tal modo que ante todo es en el ser y sólo es en el ser en la medida en que es configurado por el hombre, que es quien representa y propone.

La certeza platónica buscaba responder preguntas como: ¿cuál es tu evidencia?, ¿cómo conoces?, ¿cómo puedes estar seguro?, preguntas hechas, generalmente, por un escéptico. Los racionalistas Spinoza y Leibnitz buscaron responder con la búsqueda de la coherencia; por su parte, Kant buscó la certeza y verdad en los objetos interiores, en las representaciones interiores a priori, representaciones privilegiadas. Pero estamos de acuerdo que fue Nietzsche quien demostró que nuestro conocimiento está formado de experiencia sensible y conceptos, sensibilidad y categorías de la razón, resaltando los segundos. Aunque adoptamos la formulación kantiana nos damos cuenta que las categorías de la razón sólo son medios hacia la adaptación del mundo para fines utilitarios. La certeza, la verdad y la racionalidad parecen interesantes si contribuyen a la satisfacción y el crecimiento. En lugar de buscar una teoría de la certeza o verdad como coherencia, se debe pensar en una teoría sobre la armonía no sólo de las creencias, sino más bien de las creencias y los deseos. Una nueva forma de ver a Kant hace referencia a un pragmatismo conceptual, donde las categorías kantianas, las formas en que pensamos, las estructuras de nuestras indagaciones, son maleables. Las cambiamos cuando semejante cambio nos permite satisfacer nuestros deseos haciendo las cosas más manipulables. Así, en el criterio de verdad, de certeza, se introducen los deseos. La finalidad del pensamiento refiere a un relato técnico e instrumental.

Hay un supuesto subyacente de occidente: la verdad es de algún modo la cuestión de la superación del débil por el fuerte: intelecto sobre el deseo sensual; la gracia sobre el pecado; lo racional sobre lo irracional, la voluntad humana sobre el entorno humano y no humano. Pero esta concepción de verdad se relaciona directamente con el poder. Conocimiento, verdad, certeza como poder de dominio, bajo la idea de Nietzsche: lo que nos mueve es el poder, las relaciones de poder constituyen la esencia humana.

Conocimiento. El conocimiento debe entenderse como adaptación, como mecanismo de adaptación, no como representación. El conocimiento se aleja de la idea de ser una representación de la realidad, de ser un reflejo mejor o peor de la naturaleza o realidad, desde una tesis antirepresentacionalista se afirma que el conocimiento no consiste en la captación de la realidad en sí, sino en la manera de adquirir hábitos para hacerle frente. La idea de verdad como correspondencia entre proposición y realidad es con ello abandonada. La idea de contrastar nuestras ideas con algo 
externo es ociosa, en la búsqueda de la verdad. Hay que elegir teorías en función de los seres que deseamos ser. Como se dijo anteriormente, hay que identificar el sentido de la vida con obtener lo que se desea, con imponer nuestra voluntad, considerar las ideas que nos permitan disponer de las cosas, manipularlas, de forma como dictan nuestros deseos. El conocimiento entendido como las creencias, teorías y conceptos se considera como una manera de enfrentar la realidad con las fuerzas causales, para modificarlas y modificarnos, sin necesidad de apelar a la idea de conocimiento como representación del mundo. La exactitud de un conocimiento está dada no por su mejor o peor capacidad de representar el mundo, sino por su utilidad (Rorty, 2000: 217), para lograr satisfacer las necesidades humanas, ya sea individuales, organizacionales o sociales. De acuerdo con Rorty, parece que en cuanto abandonemos la idea de que la finalidad del discurso es representar con precisión la realidad dejaremos de interesarnos por distinguir las construcciones sociales - enunciados descriptivos como leyes, teorías, conceptos, y como enunciados prescriptivos como normas y valores- de las demás cosas y nos limitaremos a discutir acerca de la utilidad de los constructos sociales alternativos.

\section{El discurso administrativo}

El concepto de satisfacción de necesidades o preferencias [deseos] que señala el pragmatismo, especialmente de Rorty, bien puede identificarse con el de los objetivos organizacionales. El pragmatismo se centra en la utilidad de los constructos, en este caso el discurso administrativo como un discurso que busca ser útil. Lograr satisfacer las necesidades de la organización significa alcanzar los objetivos de la organización. El discurso administrativo refiere precisamente a ello. Koontz (2004) nos dice que "la administración es el proceso de diseñar y mantener un entorno en el que, trabajando en grupos, los individuos cumplan eficientemente los objetivos específicos. Koontz amplía esta definición señalando cinco puntos:

- Cuando se desempeñan como administradores, los individuos deben ejercer las funciones administrativas de planeación, organización, integración de personal, dirección y control.

- La administración se aplica a todo tipo de organizaciones.

- Se aplica a todos los niveles organizacionales.

- La intención de todos los administradores es la misma: generar un superávit.

- La administración persigue la productividad, lo que implica la eficacia y la eficiencia. 
Con respecto a la cuarta afirmación, conviene aclarar a qué se refiere. Se administran las organizaciones para generar un superávit. En las organizaciones comerciales, el superávit son las utilidades, el dinero. La necesidad fundamental por satisfacer es la utilidad. Este deseo de búsqueda de utilidad corresponde a toda organización lucrativa. El discurso administrativo se convierte en un medio para lograr tal fin, para la satisfacción de tal necesidad. Con relación a la primera afirmación, las cinco funciones de la administración — planeación, organización, integración, dirección y control - conforman un sistema conceptual, cuya "coherencia" la recibe por el criterio de lo que es útil para el logro del superávit, sin preocuparse por la dispersión enunciativa y la gran flexibilidad, al permitirse convivir enunciados de diversas teorías y áreas de conocimiento ${ }^{7}$. El respetar algún criterio teórico no está dentro de sus preocupaciones, conviven conceptos de la propuesta clásica administrativa, como el humano-relacionismo, el comportamiento humano, las teorías del "mejor camino", la teoría de contingencias, en los cuales se observan conceptos conductistas como no conductistas. Es una variedad de conceptos donde lo que importa es ofrecer algo que pueda servir para el logro del superávit. Todo ello desde una perspectiva o tradición pragmática, como afirma Nietzsche: una creencia es verdadera no porque represente exitosamente la realidad, sino por ser una regla de acción que proporciona ventajas, para obtener el beneficio esperado, como una elección racional. En este sentido, la teoría de elección racional $^{8}$ se puede ubicar ahora en el pragmatismo.

Lo que une la dispersión conceptual y enunciativa es el objetivo básico, la búsqueda del superávit, del lucro. Koontz nos recuerda que, en estricto sentido, el objetivo lógico y públicamente aceptable de la totalidad de los administradores de todo tipo de organizaciones es obtener un superávit, en el caso de las organizaciones lucrativas son las utilidades. El discurso administrativo nos enseña cómo establecer el medio adecuado para tal fin; esto es, establecer un ambiente adecuado en el que el personal pueda lograr las metas de grupo con la menor inversión de tiempo, dinero y materiales, así como la menor insatisfacción personal.

\footnotetext{
${ }^{7}$ De acuerdo con el pluralismo metodológico, se puede encontrar en el discurso administrativo, tanto la idea de que no existe el mejor camino, como el que lo hay; propuestas individualistas como colectivistas, propuestas empiristas como teleológicas, formalistas como narrativas, proposiciones fundadas en una racionalidad metodológica, como proposiciones que se pueden ubicar en una racionalidad normativa.

${ }^{8}$ Desde luego, la idea de elección racional y la cuestión económica no pertenecen a la tradición pragmática, por ello simplemente hago señalamientos. La relación que pretendo hacer es entre pragmatismo con el discurso administrativo, no con la economía.
} 
¿Qué debe preocupar al discurso administrativo? El conformar una compañía de excelencia, esto es, que eleve la rentabilidad, el desempeño financiero; alejado de preocupaciones epistemológicas, aunque también del bien común, se va a lo práctico. Un enunciado o un concepto, no importa si pertenece a una teoría motivacional de contenido o de proceso, no importa si pertenece a Abraham Maslow o a Burrhus Frederic Skinner, lo que importa es si eleva la rentabilidad o no, si permite un mejor desempeño financiero o no. La visión del discurso administrativo es pragmática, sin "casarse" con alguna teoría, sugiere:

- Orientarse a la acción

- Informarse acerca de las necesidades del cliente

- Promover el espíritu empresarial

- Obtener alta productividad

- Regirse por una filosofía basada en lo valores de sus líderes

- Poseer una estructura organizacional sencilla y escaso personal administrativo

- Centralizadas o descentralizadas, dependiendo de sus circunstancias

El conocimiento no consiste en la captación de la realidad en sí, sino en la manera de adquirir hábitos para hacerle frente, para manejarla, manipularla exitosamente, en la búsqueda de sus objetivos de superávit, utilidades, rentabilidad; es decir, se inscribe en la tradición pragmática.

Para Koontz, el discurso administrativo es tanto arte como ciencia. Se debe señalar que su análisis carece de profundidad. En un libro de 804 páginas, le dedica a este asunto tres párrafos modestos y superficiales. En este tema epistemológico, la modestia de su análisis - al no tomar en cuenta conceptos fundamentales que la filosofía de la ciencia o la epistemología proponen - señala que ve al discurso administrativo como algo que no requiere mayor preocupación de este tipo, y que conviene irse a la acción, a la práctica.

Este mismo autor afirma que la administración es un arte porque nos enseña a hacer algo en vista de las realidades de una situación. Caracteriza a la ciencia sin tomar en cuenta las propuestas de los positivistas o pospositivistas, como conocimientos organizados, y señala que el discurso administrativo es ciencia porque precisamente tiene sus conocimientos organizados. Al parecer para ello tenía en mente los co- 
nocimientos que encontramos en la estructura organizativa de lo que han llamado proceso administrativo: planeación, organización, integración, dirección y control, como si ello bastara para la construcción de una ciencia. ¿Y la sistematización, la coherencia, el sistema hipotético deductivo/deducibilidad? ¿Dónde quedan en tal proceso administrativo? Al parecer el criterio de estructuración de conceptos en el proceso administrativo, más allá de la coherencia lógica, fue la utilidad. Métete al cuarto que necesites meterte, que señala James. Michel Foucault recuerda un texto de Borges (Foucault:1997) en el que muestra una organización de conceptos o seres muy interesantes, sacados de "cierta enciclopedia china", veámoslos:

\section{Cuadro 1 \\ Taxonomía borgiana}

Los animales se dividen en

a) pertenecientes al emperador,
b) embalsamados,
c) amaestrados,
d) lechones,
e) sirenas,
f) fabulosos,
g) perros sueltos,

h) incluidos en esta clasificación,

i) que se agitan como locos,

j) innumerables,

k) dibujados con un pincel finísimo de pelo de camello,

1) etcétera,

m) que acaban de romper el jarrón,

n) que de lejos parecen moscas"

Fuente: Michel Foucault (1997). Las palabras y las cosas, México: Siglo XXI.

La taxonomía "descubierta" por Borges (1997), como dice Foucault, es asombrosa. Es cierto, produce una risa que sacude, pero es una taxonomía, cuya ley de ordenamiento queda en lo oscuro. Cuando se piensa en personas que tienen problemas patológicos para organizar conceptos o la realidad, pensamos en esta taxonomía. Pero si ella fuera útil para el superavit en la empresa, se retomaría. Las taxonomías que ofrecen la biología y la química son ejemplos de inteligentes ordenamientos. Como se puede ver en el anterior ordenamiento de conceptos, no basta construir una estructura organizativa para que sea científica. Lo congruente, lo lógico, es una exigencia en una estructuración u organización; sin embargo, las heteropatías inquietan. En el discurso administrativo, sin caer en el ejemplo extremo de la taxonomía de la enciclopedia china, parece que encontramos una ligera sombra de ese fenómeno, el ordenamiento muestra que los conceptos tienen un aire de familia. 
Siguiendo las ideas del pragmatismo, el ordenamiento conceptual que se da en el proceso administrativo en general y en particular propuesto por Koontz, no se debe a alguna heteropatía, sino a una cuestión práctica. Conviene por ello recordar un texto de James, uno de los representantes importantes del pragmatismo, que recuerda al instrumentalismo, que ya en el escritor italiano Papini se puede ver:

No tiene dogmas ni doctrinas, salvo su método (Douglas, 2001). Como el joven pragmatista italiano Papini ha dicho acertadamente, yace en medio de nuestras teorías, como el corredor de un hotel. De él se abren innumerables cámaras; en una es posible encontrar a un hombre escribiendo un volumen ateo; en la siguiente, hay alguien de rodillas rezando para tener fe y fortaleza; en la tercera, un químico investiga las propiedades de un cuerpo; en la cuarta, se demuestra un sistema de metafísica idealista; sin embargo, todos son propietarios del corredor y todos deben pasar por él si desean un medio práctico de entrar en sus respectivas habitaciones o salir de ellas. La sugerencia es: entra al cuarto que necesites meterte.

Así, pues, el método pragmático significa que no hay resultados específicos hasta el momento, sino sólo una actitud de orientación: la actitud de apartar la vista de las primeras cosas, principios, "categorías", necesidades supuestas; y de mirar hacia las últimas cosas, frutos, consecuencias, hechos.

La sugerencia es: entra al cuarto que necesites meterte. De igual forma, en el proceso administrativo, siguiendo la metáfora de Papini, es como un "hotel" con diversos pisos e innumerables cuartos. Cinco pisos para seguir el modelo de Koontz: planeación organización, integración, dirección y control. En cada piso hay "innumerables" cuartos, algunos de ellos: planeación estratégicas, tipos de planes; naturaleza de la organización, organización formal e informal, el departamento, tramo de control, organigramas, autoridad de línea y staff; selección de recursos humanos, evaluación del desempeño; factores humanos y motivación, liderazgo, comités y equipos, comunicación; sistema y proceso de control, técnicas de control, tecnología de la información, administración de la calidad, control global.

Sin meternos al problema del Babel administrativo, de un esquema conceptual que dista de la sistematicidad de cualquier otra área de conocimiento, como el de la física, química, economía, sociología o antropología, donde se busca la sistematicidad y se busca un esquema hipotético deductivo para poner a prueba las teorías ${ }^{9}$,

\footnotetext{
${ }^{9}$ Mario Bunge pretende meter el discurso administrativo en el ámbito de las técnicas, pese a ello los teóricos mencionados del discurso administrativo insisten en que se considera a la administración dentro de la ciencia
} 
en el discurso administrativo priva el criterio pragmático, para la ordenación de conceptos y de enunciados. Métete al cuarto que necesites meterte. El diseño del "hotel" administración, la construcción constante de cuartos, se da bajo el criterio de utilidad, de alcanzar los objetivos organizacionales, de satisfacción de sus necesidades y deseos, que en las organizaciones que buscan el lucro será la ganancia, la rentabilidad, la productividad, la eficiencia, la eficacia, el buen desempeño financiero. Veamos una presentación de tal esquema:

\section{Cuadro 2}

\section{Funciones administrativas}

\begin{tabular}{ccccc}
\hline PLANEACIÓN & ORGANIZACIÓN & INTEGRACIÓN & DIRECCIÓN & CONTROL \\
\hline Tipos de planes & Naturaleza de las & Administración & Factores & Sistema y \\
Objetivos & organizaciones & y selección de & humanos y & proceso de \\
Misión & Estructura & recursos humanos & motivación & control \\
Estrategia & organizacional & Evaluación del & Teoría X y Y & Técnicas de \\
Planeación & Departamenta- & desempeño y & de Mc Gregor & control y \\
estratégica & lización & Estrategias & Teoría de las & tecnología de \\
Matriz TOWN & Organización & de desarrollo & necesidades & la información \\
Matriz de & matricial & profesional & de Malow & Productividad, \\
portafolios & Autoridad de línea/ & Administración & Teoría ERG & administración \\
Toma de & staff & del cambio & Teoría de las & de \\
decisiones & Empowermwnt & & expectativas & operaciones y \\
& & & & administración \\
& & & & de la calidad \\
\end{tabular}

Fuente: H. Koontz y H. Weihrich (2004). Administración, una perspectiva global, 12a. ed., México: McGraw-Hill.

¿Por qué conviven en el mismo esquema las teorías psicológicas diversas y hasta contradictorias? ¿Cómo hacer que convivan en un mismo esquema conceptual la teoría geocéntrica de Ptolomeo y la teoría heliocéntrica de Copérnico, o la teoría física de Aristóteles y la física de Newton? Sólo los criterios pragmáticos posibilitan ello, además de la flexibilidad del lenguaje (Koontz y Weinrich, 2004). Parece olvidar que al adoptar una concepción lo compromete a uno con su visión de lo verdadero y falso y prohíbe adoptar cualquier otra postura rival. Normalmente, encontramos compromisos marxistas, neoliberales, por un lado; por otro, conductistas, psicoanalistas, positivistas, relativistas, entre otros (Alasdair MacIntyre, 1994). Teorías opuestas no pueden aplicarse al mismo tiempo, pero sí separadamente. Nuevamente este eclecticismo teórico y metodológico puede encontrar una mejor comparación con la ingeniería, ciencia aplicada que con teorías básicas. 
Al parecer el discurso administrativo participa y no se contradice en ciertos prejuicios de la tradición pragmática como los que se han señalado, por lo que se puede considerar a la tradición administrativa como una forma particular de la tradición pragmática.

\section{A modo de conclusión}

En el discurso administrativo se pueden encontrar los mismos prejuicios de la tradición pragmática. Esto es, en la administración se privilegia lo útil, lo eficaz, lo que da resultados, las predicciones que se objetivizan, más que la especulación. De la misma forma, la administración resalta lo contextual (como señala la teoría de contingencias), la importancia de lo prudencial, el no adherirse vehementemente a alguna creencia. La administración confía en un criterio instrumentalista de los enunciados preferenciales, es decir, en predicciones exitosas. Contra la búsqueda de la última verdad privilegia la nueva forma de certeza: lo que me permite alcanzar resultados o satisfacer mis necesidades individuales u organizacionales. El discurso administrativo no muestra mucha preocupación por las cuestiones especulativas: como alcanzar la verdad. Contra la idea moderna de relacionar todo prejuicio con error, me parece que no siempre es así, hay prejuicios adecuados y que deben mantenerse, por lo que deben someterse a la reflexión constante.

Puedo resumir lo planteado en este trabajo mostrando las similitudes entre la tradición pragmática y el discurso administrativo; en ambos podemos encontrar el considerar como importante: lo histórico, lo eficaz, los resultados, la predicción, lo prudencial, la racionalidad instrumental (medio-fin), lo práctico, la búsqueda de resultados, el poco aprecio por lo especulativo, la búsqueda de satisfacción de nuestros deseos, el alcanzar los objetivos.

\section{Referencias}

Borges, Jorge Luis (1997). "El idioma analítico de John Wilkins”. Otras inquisiciones, España: Alianza Editorial.

Douglas R., Anderson (200I). "La ética en los negocios y la actitud pragmática". La ética en los negocios de Robert E. Frederick (compilador), México: Oxford. 
Foucault, Michel (I997). Las palabras y las cosas, México: Siglo XXI.

GADAMER, G. HANS (I998). "La historicidad de la comprensión como principio hermenéutico". Verdad y método, Madrid: Sígueme.

Gannon, Martín (1994). "Perspectiva de la administración". Administración por resultados, México: CECSA.

Koontz, H. y Weinrich H. (2004). Administración, una perspectiva global, 12a ed., México: McGraw-Hill.

(2002). "La base de la teoría y la práctica de la administración global”. Elementos de administración, enfoque internacional, $6^{\mathrm{a}}$ ed., México: McGrawHill.

MacIntyre, Alasdair (I994). "La racionalidad de las tradiciones". Justicia y racionalidad, Barcelona: EIUNSA.

Mercado, Salvador (1990). "Aspectos básicos de la administración”. Administración aplicada, teoría y práctica, México: Limusa.

RORTY, RICHARD (I993). "Heidegger, contingencia y pragmatismo". Ensayos sobre Heidegger y otros pensadores contemporáneos. Escritos filosóficos 2, traducción de Jorge Vigil Rubio, Barcelona: Paidós.

(2000). El pragmatismo, una versión, España: Ariel Filosofía.

Strickland, Thompson (200I). "El proceso de la administración estratégica". Administración estratégica. Conceptos y casos, México: McGrawHill.

Velasco, Ambrosio (2000). "Ética e historia: ¿universalismo ético o relativismo moral?", en Luis Villoro (Coordinador). Los linderos de la ética, México: Siglo XXI, UNAM.

(2004). "Hacia una filosofía social de la ciencia en Karl R. Popper”. Signos filosóficos, año/vol. VI, No. 11, Universidad Autónoma Metropolitana - Iztapalapa, México. 